DOI: $10.34170 /$ ed.2019.2707-370X.2(1)-3

UDC 331.101.262:005.336.4]:316.472.47

OLGA REVINA

$\mathrm{PhD}$ in economics, Certified Investors in People Adviser Chairperson, QUBF LLC (G),

Doha, State of Qatar;

e-mail: olga.revina@qubf.org

ORCID: 0000-0002-4518-0434

\title{
PARTNERSHIP MODEL IN HUMAN POTENTIAL DEVELOPMENT DRIVEN BY INTELLECTUALISATION OF ECONOMY
}

In the sphere of philosophy of economics the development of human potential is unquestionably the basic factor of economic and social sustainable growth which is evidenced by renowned scientific research and leading international institutions. In particular, the process of intellectualization of economy is based on public experience, human knowledge, skills and innovative capabilities, while at the same time an important influence is carried out by the modern process of critical thinking. Due to effective development of such capabilities there is a growing need among researchers to equip their methodology with new generation trends and the most advanced mechanisms in human development in order to further disseminate the practical implementation of these tools aimed to support in achieving sustainable success.

Relaying on the analysis of the current pertinent theories the author suggests to explore people partnership model which broadly refers to wide range of findings, functioning and structure in human potential management and development for the purpose of polyphonic provision of any organizational entity of the society. The author proposed to consider this people partnership model as a synergistic system of personnel interaction, which includes an effective combination of two key components, such as economic and social partnership within any organization in order to achieve efficient empirical indicators. The methodology suggested by the author in regards to people partnership is based on economic and social interaction of the involved parts, when all participants of the process have the motivation to meet the needs of all potential stakeholders. A prerequisite for achieving such a synergy is the process of providing a holistic model for an effective utilization of human intellectual capabilities and, in parallel, to unlock their synergetic potential in the framework of philosophy of economics.

The author provides a detailed explanation of partnership model and parity management while introducing the benefits of implementing this concept within an organization as a modern platform of people interaction and targeted actions thereby enabling positive returns and improvements in social aspects and further renewal of modern human life. As a result, the current research arrives at a conclusion that based on people's economic partnership and social interaction such modern managerial practices will lead to potential harmonization of the relations among all participants of the socio-economic activity. 
This partnership approach proves the following thesis: people collaboration creates a tendency for rapid development of human potential when it is based on a critical blend of unique human experience, innovations and creativity in critical thinking, which in the purview of globalization become vital components in the process of intellectualization of economy.

Key words: philosophy of economics, human potential, critical thinking, intellectualization of economy, parity management, economic and social partnership.

\section{Relevance of the research topic}

Modern globalised world presupposes development of human potential as a crucial driver of economic and social sustainable growth. Hence, one increasingly observes rapid changes in the eco-social internal and external environment that challenge effective education and deployment of human potential. The sphere of philosophy of economics has specifically witnessed a rapid development of human potential as an unquestionable factor of economic and social progress evidenced by scientific research undertaken within leading international institutions. According to UN studies, based on the data from 192 countries, $64 \%$ world economic growth is due to human and social potential, with natural resources and capital availability accruing the remaining $20 \%$ and only $16 \%$ respectively. Another important trend to take note of is that an increase in the level of education by $10 \%$ causes a corresponding labour productivity improvement by $8.6 \%$ [8], making human potential development a key priority of organizational strategies in various economic sectors. All of this emphasizes the relevance of research into the areas of human potential management improvement calling for its prioritized development within any organizational entity whose main objective is to perceive its staff as a decisive factor of sustainable success. The author, therefore, deems it important to stress that after numerous comprehensive studies in this field, the definition of 'human potential' is focused on human's accumulated and potential assets, such as qualities, abilities, and competencies that can be activated to achieve the socio-economic effect ${ }^{1}$.

In particular, the process of intellectualization of economy is based on public experience, human knowledge, skills and innovative capabilities, while at the same time an equally important influence is placed on process of critical thinking. Thus, we can observe a growing need among leading researchers to equip their methodology with a new generation of trends which take advantage of cutting edge mechanisms in human development to effectively disseminate the practical implementation of these novel tools in achieving sustainable success.

\section{Analysis of recent researches and publications}

A number of recent human development studies conducted by Deloitte strongly indicates a preference for a world where all human beings have the freedom to fulfill their outmost potential in life in order to attain their values. A critical analysis, served to prove the company's long stated maxim whereby development was proclaimed to be of the people, by the people and for the people. People have to partner with each

1 Revina, O. M. 2013. "The development of human potential as a factor of economic growth." 
other. By emphasizing the need for cooperation and partnership human development theory recognizes that every life is equally valuable and that a truly inclusive model of organizational enhancement must account for those who are in most need of it. Sympathetic to this ethos the 2016 Human Development Report is, thus, a significant intellectual contribution towards resolving these issues. In particular, it epitomizes strive of human development to facilitate an environment enabling us to effectively acquire new capacities whist enjoying more opportunities to use them. Presented with an increasing amount of opportunities, people get additional options for self-betterment, which is at the core of the human development approach ${ }^{2}$.

The vexing issues of human development in the process of economic intellectualization are reflected in the scientific work of many prominent Ukrainian researchers: V. Antonyuk, V. Bazilevich, V. Bliznyuk, A. Bazylyuk, V. Heyets, O. Grishnova, V. Gurnak, G. Dmitrenko, T. Zayats, A. Kolot, G. Kucheruk, E. Libanova, L. Lisogor, I. Mantsurov, M. Makarenko, O. Tsymbal, A. Chukhno, and others.

Significanttheoretical, methodological and practical foundation for the study of the formation of intellectual economy was likewiselaid down by such internationally renowned economists as: D. Bell, M. Young, A. Toffler, P. Drucker, P. Heilbroner, T. Stuart, T. Sakaya, and others ${ }^{3}$. Specifically, Elton Mayo has examined a wide variety of tools for improving human productivity, focusing on the unification of the mutual staff interests and organizational administration as a firm basis of parity approach. Mayo's contribution to management theory has consequently helped pave the way for modern human relations management methods ${ }^{4}$.

In particular, working within this framework M. Porter outlined the prominent role of education in increasing competitive advantages of any organization which strives for constant growth in the quality of its human resources. Improving people's personal and psychological skill set while lifting their level of education and culture is, thereby, an undoubtedly important prerequisite for the formulation and implementation of scientific, economic, and sociocultural development as a whole $\mathrm{e}^{5}$.

\section{Setting the tasks}

When analyzing large scale industry transformations researchers agree that the processes of economical intellectualization puts forward specific requirements to be met by organizations leading to the formation of a fundamentally revolutionary concept for human potential management and development. It should be further noted that the intellectual economy is uniquely characterized by a special commodity - knowledge, which, unlike other resources, is not in danger of depletion, limitation as well as defying the means of traditional consumption. Solely dependent on an employee's operating proficiency (the presence or absence of personal competencies) to perform intellectual work, accumulation, processing and generation of new knowledge, this resource is only affected by the aforementioned parameters.

2 Human Capital Trends 2016.

3 Sakajja, T. 1999. Knowledge generated cost or the History of the future.

4 Theory of E. Mayo.

5 Porter, M. 1993. International Competition. 
Taking into account a plethora of recent studies carried out by various reputable global institutions we clearly see a trend towards the implementation of innovative technologies and management practices in human potential development being considered a productive approach aimed at achieving effective economic and social outcomes both for particular organizational entities as well as society as a whole. As a result, in 1992a fruitful culmination of joint efforts by the British scientists, representatives of numerous employers and employees Associations brought about an emergence of the Investors in People Standard to be used as an authoritative guideline for a holistic developmental framework tasked with improving organizational performance through human potential development. Today Investors in People Standard is recognized as an established benchmark encompassing the best global practices in people management ${ }^{6}$.

This being the case, the question of addressing the specifics of the formation and realization of human potential within various organizational networks in the context of intellectualization of the economy and in accordance with the modern transformational processes and trends is still a pressing task which we shall now turn to. In particular, practical experience of achieving incremental employee competence growth strongly suggests the need for an approach to human potential development to be based on the following integral pillars: concrete strategic management, a structured account of the prospects of personal improvement, an increase in peer cohesion through investments in professional training, favourable organizational environment, innovations and constant sustainable benchmarking. The specifics of maximizing returns on investments in human potential development needs to be determined in the context of intellectualization, transformational processes and trends of a knowledge-based economy.

\section{Presenting the research statement}

The process of the intellectualization of economy is based on human knowledge, skills, experience and competencies. Accordingly, there is a growing need among researchers to equip their methodology with a new generation of trends and mechanisms in human potential development applicable within any organizational structure (public or private) in order to further disseminate the practical value of these critical tools in unlocking and utilizing human potential while contributing to the success of any organization and the society as a whole. One such approach is VI generation Investors in People Standard which offers globally recognized methodology in human development reflecting latest workplace trends lending support to people who are eager to fully tap into the hidden reserves of their personal and professional potential. Specifically, the VI generation IIP framework underpins 9 indicators of success attainment inherent in honing an effective employee collaboration mechanism which allows us to achieve outstanding interpersonal result. The following 9 indicators are: leading and inspiring people; living the organization's values; empowering and involving people; managing performance; recognizing and rewarding high performance; structuring work; building capability; delivering continuous im-

\footnotetext{
6 Investors in People.
} 
provement whilst facilitating sustainable success ${ }^{7}$. Based on latest research in people development the author would like to further outline the key principles of human potential management to be incorporated in the framework of any successful organizational entity. Crucial when applied to any organizational structure and economic sector these 4 principles have been proven to be a significant boost in raising both individual and organizational performance:Consequently, the key principles introduced above are specifically geared towards fostering systematic planning, effective communication, sequential implementation and objective monitoring as cornerstone mandatory guidelines of any broad refinement ${ }^{8}$. Observing these critical tenets, likewise, promotes an optimization of labor activity while at the same time serving as the basis for ensuring a sustainable increase of efficiency in all branches of organizational development.

The methodical principles for determining effective implementation of HR management mechanisms, particularly in terms of training and development, whilst taking into account the transition from the cost estimation of human potential development to the investment-oriented method, is based on the use of the indicative approach (empirical indicators). By motivating personnel to achieve the best end results it promotes a host of well-balanced assessment procedures designed to improve any individual performance.

The paradigm of human potential management and development is, thus, based on a holistic concept of management defining it as an inherent social activity. The principal part of this concept is determined by taking into account such important by-products of human collective behavior as values, incentives, motives and interests. The organizational approaches in improving efficiency of human potential should, therefore, give credit to the process of economical intellectualization which favourably transforms of the perception of an individual from being a "resource" to becoming a "partner", all of which contributes to the gradual improvement of personnel management approaches in accordance with rising international trends and standards ${ }^{9}$. Furthermore, an additional leap in efficiency of organizational performance can be achieved by implementing a holistic, conceptual approach to the development of management techniques in order to accurately evaluate organizational performance and output by identifying areas requiring further development. A subsequent step would be to maintain an appropriate corporate culture aimed at motivating employees to achieve an outstanding performance on both individual and organizational levels by taking advantage of the opportunity to positively transform your business via proper prioritizing of human potential development.

7 A new Framework. A new High Standard Introducing the VI generation.

8 Revina, O. M. 2014. "Key principles in managing performance through human capital development."

9 New managerial paradigm. 
We've seen that applying relevant principles of a holistic conceptual approach stimulates a set of favourable conditions for effective management, healthy corporate and social climate, calling for a productive identification of an individual with the goals of an organization. By contributing to the achievement of the delicate balance of operational interests of all parties involved this approach exerts equal positive impact on internal and external organizational environment.

So would it be necessary to consider the significant role of human potential development in generating organizational values? The answer seems to be a straightforward yes, since the price of products and services is not only influenced by physical (material) resources, but is likewise formed through knowledge being manifested in novel technologies, experiences, skills, and economic relations at all levels with consumer, supplier, and competitor all linked by this mesh of aggregate benefits. Similarly, since as we have seen knowledge is a key factor in achieving organizational ambitions, intellectual work thereby becomes an integral foundation for the creation of such added value which ensures a continued growth of organizations and their economic competitiveness.

Systemic approaches are therefore rightly perceived as effective managerial influences on all organizational processes: communication, marketing, innovation, knowledge management. Highlighting the core features of the previously established managerial approaches such as overreliance on authority, personal dependence, economic coercion, and stifled motivation, this novel approach strongly favours a set of different motivational tools like: active participation of personnel in the processes of organizational life, concept ownership, creative involvement, shared responsibility, collaborative decision-making, team synergy, personal commitment, innovation, and knowledge management.

Management practice, thus, constantly continues to evolve, feeding conversely into the corresponding development of managerial theory. The concept of management humanization is another worthy shift from technological control in the direction towards utilizing human capital, whereby economic growth strategically depends on the development and efficient deployment of human potential.

Having undertaken a broad characterization of the current theories pertinent to the concept of human potential fulfillment the author suggests exploring the people partnership model which broadly refers to a wide range of findings, functioning as a structural template when applied to the studies of human potential management. In particular, we propose to consider the above mentioned approach as a synergetic system of interpersonal interaction, which includes an effective combination of two key components (economic and social partnership) found within any organization which strives to arrive at efficient 
empirical indicators. The methodology suggested by the author in regards to the people partnership model is thereby based on such level of economic and social interaction, when all participants of the process are motivated to meet the demands of any potential stakeholders (Table 2). A prerequisite for achieving such unprecedented cohesiveness is attained through the process of providing a holistic model for an effective utilization of human intellectual capacities geared towards unlocking the synergetic potential and has been fruitfully studied within the purview of philosophy of economics.

Specifically, there are 2 key and 4 sub-elements of the suggested people partnership model which can be viewed as a platform for bolstering interpersonal exchange enabling positive returns and improvements in economic and social aspects of organizational dynamics.

As can be observed, the model above introduces a combination of social and economic partnerships whilst at the same time promoting equal opportunities for all employees in regards to professional growth and decision-making, involving setting transparent policies for people to take part in strategic and operational organizational activities. Based on a partner-interaction approach between employees (managers and subordinates) at all stages of organizational $l i f \mathrm{e}^{10}$,the people partnership model is, likewise, an integral part of the parity management approach which provides the foundation for stabilizing economic development within any and all organizational units. The employees of an organization are thereby strongly encouraged act as partners being provided with a high level of operational involvement, with established equal (parity) opportunities in development and career growth, possessing a highly incentivized interest in the ultimate successful outcome for all parties involved. The suggested conceptual approach, therefore, comprises:

- A sound platform for interpersonal synergetic interaction

- All-round empowerment and polyphonic collaboration

- Increased parity access to learning and development

- Open policy for leadership growth - "leaders produce leaders"

- People involvement in all aspects of organizational life

- Personal accountability and ownership in taking decisions

This conceptual approach further maintains a clear statement of equal opportunities policy which provides a necessary coordination and balance of interests between managers and subordinates by stimulating successful outcomes on an individual, team, and organizational levels. Acting as a partner who engages in all processes of cohesive organizational life, it is further possible to define the adherents of this concept as highly reciprocal agents involved in exceptional parity management that promotes the enhancement of human potential based on the unique collaborative experience, innovation and creativity. Other aspects of the suggested methodology, likewise, include technological innovations, favourable work conditions, democratic

10 Revina, O. M. 2014. "Principles of the concept of parity management using human potential in transportation sphere enterprises." 


\begin{tabular}{|c|c|}
\hline \multicolumn{1}{|c|}{ Definition of principles } & \multicolumn{1}{c|}{ Forms of introduction } \\
\hline Systematic Planning & $\begin{array}{c}\text { Modern approaches in planning devised to } \\
\text { improve the efficiency of organizational and human } \\
\text { capacity development }\end{array}$ \\
\hline Effective Communication & $\begin{array}{c}\text { A cascade model of information transfer using mix } \\
\text { of communicational methods for the development of } \\
\text { people and an organization }\end{array}$ \\
\hline Sequential Implementation & $\begin{array}{c}\text { A step-by-stepalgorithm of coordinated activitie- } \\
\text { semphasizing partnership for the attainment personal } \\
\text { and organizational enhancement }\end{array}$ \\
\hline Objective Monitoring & $\begin{array}{c}\text { An assessment of employee collaboration and its } \\
\text { impact on overall organizational performance }\end{array}$ \\
\hline
\end{tabular}

Table 1. Key principles in managing human potential development

leadership style, collegial decisions, trainings and professional skills improvement, overall humanization of the labor force ${ }^{11}$.

All of these serve as prerequisites for opening doors to effective "partner-partner" relationships, equal opportunities for the evolution of individual potential of both managers and staff. Indeed, parity management is an advanced managerial approach based on the interaction of all interested parties, because of their key components are - an economic and social partnership. An equally important feature is that this concept aims at achieving organizational welfare by means of establishing a working balance between managers and subordinates, promoting social justice and a lack of racial and/or national discrimination. Thus, an essential aspect of the parity management approach is to consider an individual not as an "object", but a "subject" of development, making people the main participants in the process of result obtainment. A fair system of personal performance evaluation coupled with appropriate remuneration levels are likewise at the forefront of this approach.

Let us now focus more on two major factors of people partnership model as an economic and social collaboration. Thus, the main purpose of economic partnership is to ensure organizational stability in accordance with the operational functioning of its strategic development designed to fulfill both personal and organizational ambitions. The term 'economic partnership', therefore, defines an active interaction between employees in order to organize and perfect all of the many interconnected components of multi-layered organizational processes (financial, industrial, marketing, investment and management), which in its turn ensures successful organizational activity, i.e., a balanced process of its functioning through devising a strategy for achieving long-term sustainable growth. It is important to note that the participation of each team member in the partnership model happens in accordance with the roles and functions and is based on their respective professional competencies. Efficient managerial process reflecting core economic partnership incentives is similarly based on

11 Theory of E. Mayo. 
four key principles previously introduced in the table 1: systematic planning; effective communication; sequential implementation and objective monitoring.

A more general interpretation of social partnership presents it as a special type of cooperation based on democratic principles, a system of social values and mutually beneficial relations devised and maintained in order to provide for a fair distribution of the individual results achieved by each participant of the process.

The concept is further defined as the form of coexistence of various subjects of social relations, which become partners. The parties of a social partnership determine the conditions and factors of the distribution of products, agreeing the parameters of socio-economic impact using democratic principles to achieve their respective interests. Social partnership can also be considered as a way of reconciling the interests of various social groups though a combination of cooperative methods intended to ensure effective party interaction. V. Potemkin defines social partnership as a system of mutually beneficial relations of organizational entities, which is oriented towards the general goal of supporting the as pirational stances of various people while at the same time reflecting the differences in their interests ${ }^{12}$. While, a broader definition of social partnership is understood as the social and professional ties between employers, employees and the government, serving as the foundation of all labour relations.

When scrutinizing the legal implications of this concept one is presented with two most recognized models of social partnership: bipartism and tripartism. Thus, in countries where the role of the government in the regulation of labour relations is insignificant (USA, Canada, UK), bilateral cooperation is generally practiced between employer associations and labour organizations. Bipartism is a form of bilateral social partnership which is mainly considered on an organizational level. Tripartism, on the other hand, is social partnership, which involves a three-way cooperative scheme between employers, employees and the government at both the regional and national level. Such cooperation may be permanent or irregular (only in case of aggravation of the situation).

The main aspects of the model of social partnership and its principles have successfully been formulated and embodied in the practice of the International Labor Organization (ILO) as a sanctioned legislator in this field.

Such partnership model provides an equal opportunity for people to improve their competences, constantly learn and grow, engage in responsible managerial decisions, feel motivated and as a result, demonstrate a higher level of professional performance.

Legally-wise the theory of management, likewise, links social partnership to the concept of productive, economic and social democracy which means that in practice, social partnership is carried out through a process of its participants negotiating with the outcomes of their decisions reflected in corporate documents and collective agreements. Such type of shared judicial responsibility frequently contributes to a more complete realization of economic and labour interests, a more robust advocacy of the rights of the parties which are regulated by the legislative norms. Thus, if social partnership is considered as a component of the parity management, whereby all par-

12 Potemkin, V. K. \& Jakovleva, N. V. 1998. Human social reserves: labor and management. 


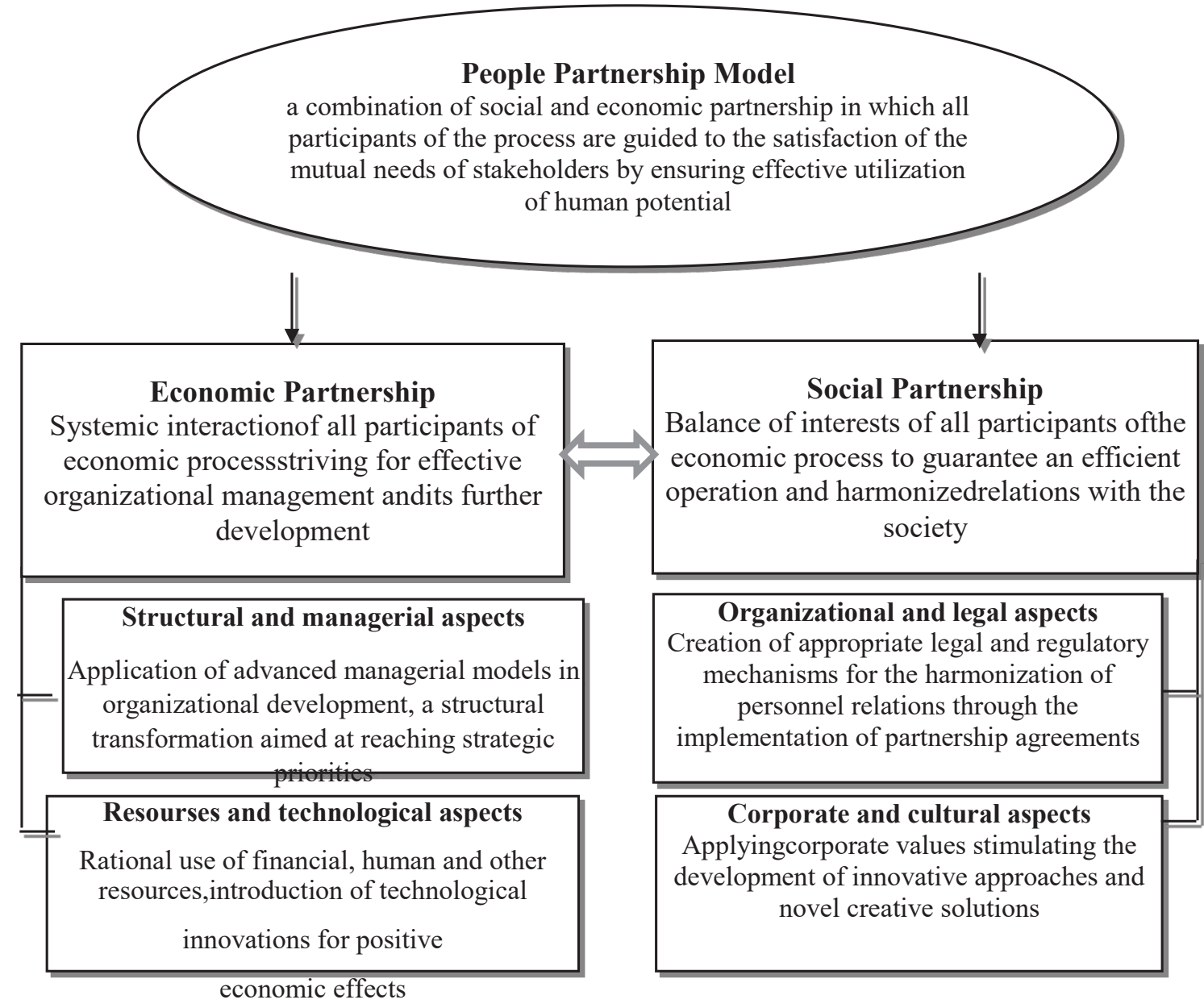

Table 2. People Partnership Model

ticipants of the aforementioned process act as partners, then the legal document reflecting their relationships may be perceived as an "affiliate partnership agreement", which becomes the alternative to the collective agreement ${ }^{13}$.

Another essential aspect which supports human potential development is viewing organizational culture as an important foundation for building corporate relations, common values, social and economic dialogue among partners of any organizational entity. Taking into account the importance of people partnership concept, with corporate values as the base of an organizational culture it is easy to see how organizational culture can genuinely contribute to the development of personal responsibility for the implementation of common values. Being the dominant outcome of good parity management reciprocal corporate climate is now increasingly seen as a crucial factor organizational efficiency bolstering its competitiveness which is attained by embracing a democratic style of leadership, proper team interaction allows all of its members to dynamically react to all of its challenges and share in all of its achievements.

Defined as corporate ethos, parity management relies on the systematization and improvement of operational principles, corporate values are used in regulating the

13 Revina, O. M. 2014. "Principles of the concept of parity management using human potential in transportation sphere enterprises." 
day-to-day activities and contribute to successful development and achievement of vision of strategic priorities. Guided by these normative tenets, employees are able to build their relationships on the principles of common values, shared managerial style, diversity and an equal opportunity, loyalty, as well as effective implementation of organizational policies and practices ${ }^{14}$.

\section{Conclusion}

The focus of knowledge-based economy is on the accumulation of intellectual capital resulting in the achievement of synergetic effects via cohesive staff interaction aimed at transforming the processes of discovery, accumulation and dissemination of information, experience and knowledge transfer. Reviewing the conceptual approaches for creating a new managerial style with favourable organizational culture in order to effectively promote the development of human potential are of equally paramount importance.

At the same time, it is important to underscore the value of responsible leadership, management efficiency, team synergies, transparent principles of collaboration, all of which are directly linked to the organization's economic performance whilst reflecting the employee satisfaction index, the policies of an effective leadership and management, intellectual and social capital.

Economic actors, who incorporate a holistic approach to effective management, namely, people management based on collaborative partnerships, are capable of generating high return providing greater opportunity for sustainable organizational development. In line with this approach, a creative economy is established on economic, social, cultural and technological aspects. The proposed initiative to introduce conceptual provisions of parity management is the path to a new paradigm of a creative economy, based on the unlimited access to the global resource of human potential.

Parity management based on people partnership is an effective approach to socio-economic cooperation, an organizational mechanism for unlocking human potential, the creation of prerequisites for the dissemination and transfer of knowledge and experience, the congregation of people around common goals and values. The author of this article has suggested the definition of parity management as a socio-economic partnership, in which all participants of the process are directed to the maximum satisfaction of the needs of all interested parties with the intention to promote effective management and development of human potential, introduction of the best managerial innovations and practices, increasing competitiveness of organizations, promoting socio-economic growth, adherence to the principles of corporate social partnership.

Conceptual provisions of people partnership model are the dominant part of the general investing in people approaches to increase the significance and the role of any individual of each particular organization and society as a whole. The social benchmark of investing in human development is to consider people values as a priority.

The economic benchmark of investing in human development is focused on supporting any organization (public or private) to demonstrate an outstanding perfor-

14 Revina, O. M. 2014. "Principles of the concept of parity management using human potential in transportation sphere enterprises." 
mance by improving management practices and through leading and inspiring people to achieve sustainable success. The people partnership model stimulates more investment in human development, to improve leadership and managerial competencies, and to transform them into a major source of sustainable growth for any particular organization, industry and society. This partnership approach proves the following thesis: people collaboration creates a tendency for rapid development of human potential when it is based on a critical blend of unique human experience, innovations and creativity in critical thinking, which in the purview of globalization become vital components in the process of intellectualization of economy.

Only an integrated set of actions of all factors ensures the integrity and individual economic reproduction enabling effective economic and social development of an organization, industries and the society as a whole. Such a set of actions will be implemented when building an improved mechanism for human potential management by promoting a culture of partnership, supporting an innovative and open society that aspires to develop sustainable human capacity, social, and economic prosperity in the context of intellectualization of the economy.

\section{References}

Deloitte. 2019. "Human Capital Trends 2016". Modified 2017 January 13. https://www2. deloitte.com/insights/us/en/focus/human-capital-trends/2016/human-capital-trends-introduction.html

Investors in People. 2019. "Investors in People". Accessed September 7. www.investorsinpeople.com

Management Solutions. 2015. "A new Framework. A new High Standard Introducing the VI generation". Created 2015 February 19. http://www.managementsolutions.bm/images/ PDFs/iip-gen-6-framework.pdf

Porter, M. 1993. International Competition, edited by Schetinin, V. D., trans. from English. Moscow: International relations.

Potemkin, V. K. \& Jakovleva, N. V. 1998. Human social reserves: labor and management. Saint-Petersburg: ISEN RAN.

Psylist.net. 2019. "Theory of E. Mayo". Accessed September 7. http://psylist.net/socpsy/00009.htm [in Russian].

Revina, O. M. 2014. "Key principles in managing performance through human capital development". Financial, economic and social factors in the development of international relations. Kyiv, June 6-7.

Revina, O. M. 2013. "The development of human potential as a factor of economic growth." Formation of market relations in Ukraine: Collection of scientific works 4(143):250-254.

Revina, O. M. 2014. "Principles of the concept of parity management using human potential in transportation sphere enterprises." Collection of scientific works of the State Economic and Technology University of Transport, series "Economics and Management" 27:35-41.

Sakajja, T. 1999. Knowledge generated cost or the History of the future. In The New Industrial Wave in the West: An Anthology, edit by Inozemceva, V. L., 337-371. Moscow: Academia.

Teororgan. 2019. "New managerial paradigm”. Accessed August 30. http://teororgan.ru/ otvety-na-ekzamen-po-teorii-upravleniya/38-novaya-upravlencheskaya-paradigma.html [in Russian].

United Nations. Ukraine. 2019. "United Nations in Ukraine”. Accessed September 8. www. un.org.ua/ua/ [in Ukrainian]. 